\title{
DISSEMINAÇÃO DE INFORMAÇÕES AMBIENTAIS VOLUNTÁRIAS: RELATÓRIOS CONTÁBEIS VERSUS INTERNET*
}

\author{
THE SPREAD OF VOLUNTARY ENVIRONMENTAL INFORMATION: \\ ACCOUNTING REPORTS VERSUS INTERNET
}

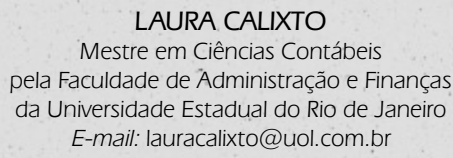

\author{
RICARDO RODRIGUES BARBOSA \\ Professor Titular do Departamento de Teoria e Gestão da Informação \\ da Escola de Ciência da Informação \\ da Universidade Federal de Minas Gerais \\ E-mail: ricardobarbosa@eci.ufmg.br
}

\author{
MARILENE BARBOSA LIMA \\ Especialização em Gestão Estratégica da Informação \\ pela Universidade Federal de Minas Gerais \\ E-mail:mblima@uai.com.br
}

\section{RESUMO}

Com o advento da Internet, grandes mudanças têm ocorrido na maneira que as empresas divulgam informações sobre a performance econômica, financeira e ambiental de suas atividades. A divulgação de informações de natureza ambiental ocorre voluntariamente por parte das empresas e essa é uma prática crescente entre elas. Acredita-se que essa é uma forma de as empresas responderem a mudanças estruturais, assim como estabelecer um diálogo mais transparente com os seus stakeholders. Este estudo exploratório teve por objetivo identificar as diferenças na divulgação voluntária de informações ambientais via Internet e via relatórios contábeis de uma amostra de 60 companhias brasileiras que exercem atividades potencialmente poluidoras. Ao comparar o conteúdo de informações divulgadas via relatórios contábeis com as informações divulgadas na Internet, observou-se diferenças significativas, ou seja, foram encontradas mais que o dobro de informações ambientais divulgadas voluntariamente na Internet. Entretanto, foram identificadas muitas divergências na forma de divulgação entre empresas do mesmo setor, tanto através da Internet como por meio dos relatórios contábeis.

Palavras-chave: Internet; Relatórios contábeis; Informações ambientais.

\section{ABSTRACT}

Due to the Internet arrival, companies have drastically changed the way to present information about economic, financial and environmental activities performance. Most companies voluntarily report environmental data and this is a growing tendency. This is probably a way companies react to structural changes, as well as establish a clearer dialogue with its stakeholders. This exploratory study aimed to identify the differences between disclosing environmental voluntary information on the Internet and through accounting reports from a sample universe of 60. Brazilian companies performing potentially polluting activities. There were meaningful differences between the information contents in accounting reports and Internet data. More than the double of the amount of voluntary environmental information was found on the Internet. Nevertheless, there were a lot of discrepancies in the way companies in the same field reported information both via the Internet and in accounting reports.

Keywords: Internet; Accounting Reports; Environmental Information. 


\section{INTRODUC̣ÃO}

A gestão da informação nas organizações tem como foco o público interno e externo, além dos vários meios de tratar e distribuir as informações estratégicas empresariais. A divulgação de informações contábeis é um dos temas abordados na gestão da informação, que estuda de que forma as empresas cumprem essa tarefa. As informações que as organizações divulgam para seus públicos são de vários tipos: financeiras, econômicas, contábeis, informações direcionadas a fornecedores, a clientes, a clientes em potencial, à comunidade de um modo geral, além de informes publicitários sobre variadas temáticas. A comunicação das empresas com o seu ambiente externo é feita com muitos objetivos, desde o cumprimento de exigências legais à publicidade e observe-se que há informações disponibilizadas por empresas de vários setores direcionadas para o meio ambiente.

É crescente o número de empresas que divulgam informações ambientais em seus relatórios contábeis, um reflexo da preocupação em tornar públicas as suas ações. Com o advento da Internet, grandes mudanças têm ocorrido na maneira como as empresas divulgam informações sobre a performance financeira e ambiental de suas atividades. A preocupação com o meio ambiente e a forma de se relacionar com ele, para garantir a confiança dos clientes e se adequar às suas exigências, têm levado muitas empresas a comunicarem suas práticas ambientais.

$\mathrm{Na}$ revisão bibliográfica realizada até a presente data, foram encontrados vários trabalhos que identificaram a divulgação, ainda incipiente, de informações ambientais no Brasil e em outros países, num índice de evidenciação desigual e de difícil análise, por setor específico ou na junção de vários. Entretanto, não foram abordadas na literatura contábil brasileira as diferenças que envolvem a divulgação de informações de modo tradicional, nos relatórios contábeis e na Internet. Portanto, este estudo tem por objetivo identificar as diferenças na divulgação voluntária de informações ambientais, via Internet e via relatórios contábeis, de uma amostra de companhias brasileiras que exercem atividades potencialmente poluidoras (petroquímica, siderurgia e metalurgia, papel e celulose, energia elétrica, alimentos, transportes, mecânica, saneamento, mineração e têxtil) disponíveis no site da Comissão de Valores Mobiliá- rios - CVM, da própria empresa e presentes no ranking das maiores e melhores, publicação da revista Exame de 2005.

A importância desta pesquisa está no fato de este assunto não ter sido abordado na literatura brasileira. Os resultados dessa verificação poderão contribuir para a uma nova abordagem no debate sobre as formas e conteúdo divulgados pelas empresas, sobre $\mathrm{o}$ aspecto ambiental de suas atividades. O que motivou este trabalho foi uma pesquisa elaborada por Razeed e Considine (2003). Os autores comparam a divulgação feita por empresas americanas e australianas. Pretende-se aplicar a mesma metodologia, adaptando-a para uma amostra de companhias brasileiras.

Para fins de limitação, a pesquisa trata somente das informações relacionadas com o meio ambiente, buscando identificar as diferenças na divulgação de informações via relatórios contábeis disponibilizados na Internet ou nos meios tradicionais, ou seja, a cópia impressa e as informações disponíveis nos websites de uma amostra de empresas brasileiras potencialmente poluidoras, no período 2005. Deve ser considerado o fato de que as informações divulgadas na Internet são voluntárias, não seguem um padrão e são comparadas com informações divulgadas obrigatoriamente, por força de lei, os relatórios contábeis. Entretanto, as informações de natureza ambiental presentes nesses relatórios, também, são divulgadas voluntariamente. Por ser um estudo exploratório, não foi possível formular hipóteses, mas o mesmo contribuirá para a formulação em pesquisas futuras.

Quanto à classificação da pesquisa, trata-se de um estudo exploratório e, quanto aos procedimentos metodológi$\cos$, foram utilizadas a pesquisa bibliográfica, a pesquisa documental e a estatística descritiva para análise dos dados.

O trabalho está dividido em capítulos e além dessa introdução, o segundo apresenta o referencial teórico sobre o tema, com ênfase nos aspectos conceituais de informação, informações contábeis, contabilidade ambiental e pesquisas anteriores sobre o tema; em seguida foram apresentados os procedimentos metodológicos. Logo, são apresentados os resultados deste estudo exploratório e as considerações finais.

\section{REFERENCIAL TEÓRICO}

\subsection{Informações e Internet}

A evolução da informática, o deslocamento da economia para o setor de serviços e o enfoque no atendimento a clientes são sinais evidentes de que mudanças estão acontecendo de forma assustadoramente rápida. O aumento de informações e a velocidade com que trafegam traz instabilidade para a sociedade. No ambiente empresarial de hoje, altamente competitivo, instável e repleto de riscos, a arma principal do empreendedor é informação estratégi- ca ou simplesmente informação. Ter a informação certa no tempo certo é algo que pode colocar tanto uma organização quanto uma pessoa passos à frente da concorrência e o que caracteriza, especificamente, esse fato é a era da informação, ou seja, é a organização de nossa sociedade baseada na geração, obtenção e aplicação de informação.

Informação não pode ser formalizada como o dado, através de uma teoria lógica ou matemática, mas pode ser caracterizada como algo significativo para alguém. Quan- 
to ao conceito de informação, de acordo com Padoveze (2002, p. 45), "informação é o dado processado de forma a ser entendido pelo receptor". Para Miranda (1999, p.285), informação é o conjunto de dados organizados de modo significativo, sendo subsídio útil à tomada de decisão. Já o conhecimento é uma abstração interior e pessoal de algo vivenciado por alguém. O conhecimento só existe no âmbito subjetivo, não pode ser representado como o dado ou a informação, pois se relaciona com algo existente no mundo real, do qual se tem experiência.

Um dos meios de comunicação mais populares, atualmente, a rede mundial de computadores, ou simplesmente Internet, começou a ser desenvolvida nos Estados Unidos da América na década de 1960, durante o período da Guerra Fria e o objetivo principal era não possuir um centro gerenciador de suas informações, em razão da sua vulnerabilidade. A sua utilização expandiu-se no meio acadêmico a partir da década de 1970. No início da década de 1990, foi criada, na Suíça, a Wold Wide Web - www, termo utilizado para exprimir a teia de alcance mundial. (MOLLETTA, 2002, p. 31).

A Internet, de acordo com Brandão (2004, p. 3), foi projetada para permitir o compartilhamento de dados e criar um sistema de comunicação único e centralizado e tornou-se comercial e amplamente difundida, a partir do início da década de 1990. A Internet contribui de diversas formas para a disseminação de dados, informações e a partir deles, é possível criar conhecimento nas instituições de ensino, instituições públicas e em instituições privadas, assim como em quaisquer outras formas de associação com o objetivo de produzir algo novo ou examinar de formas diferentes o que está disponível. Além de ser uma fonte de informações para diversos fins, atualmente a Internet é um dos principais meios de comunicação, que permite a transmissão de textos, arquivos, imagens, sons e voz.

A natureza interativa da Web permite aos seus usuários um engajamento muito mais ativo do que o possibilitado pela utilização de outras tecnologias. Com a Web, o usuário busca a informação que deseja, na dosagem que lhe é mais conveniente, enquanto através de outros canais isso não é possível. A velocidade da Internet é particularmente relevante no caso da divulgação de informações financeiras de uma empresa, pois a capacidade de reação rápida do investidor pode significar a diferença entre ganhar ou perder na disputa por uma oportunidade de investimento. A extensa conectividade da Internet permite que pessoas e organizações adquiram informação de forma muito mais fácil e barata do que já foi possível com outras tecnologias. Essa acessibilidade a informações que nem mesmo estariam disponíveis através de outros meios gera uma nova realidade na qual empresas poderão adicionar valor aos seus serviços através de uma efetiva coordenação das fontes provedoras de informação.

Se a facilidade de uso da Web pode ser, ainda, um tema em discussão (KESSLER, 1998), identificou que um dos principais fatores para o vertiginoso crescimento da Internet nos últimos anos é uma maior simplicidade de sua utilização, se comparada a outras tecnologias. Essa maior simplicidade de uso se deve à sua interface gráfica padronizada e à crescente familiaridade dos usuários no uso de computadores. Espera-se uma postura muito mais ativa por parte do usuário da informação do que acontece diante de outros canais tradicionais de divulgação das informações financeiras. Esse foco no usuário mais ativo está em sintonia com a estratégia de atender a quem está mais disposto a buscar a informação de seu interesse.

Com o passar do tempo, quanto maior a necessidade de proximidade das pessoas, maior valor foi sendo agregado às informações. Com o aparecimento da escrita, o valor das informações não se apagou e a sua conservação passou a receber mais atenção. Todas as mudanças foram e continuam sendo possíveis, a partir da quebra de paradigmas, que é de extrema importância para o processo evolutivo da humanidade e a maneira como se adquire e utiliza conhecimento.

\subsection{Divulgação de informações e informaçôes contábeis}

Com o aumento progressivo do poder de disseminação e acessibilidade de informações, as empresas divulgam por meio da Internet grande número de informações sobre o seu histórico, a sua missão, negócio, relações sociais com a comunidade interna e externa, produtos e serviços, além de informações contábeis e financeiras.

As empresas, de um modo geral, divulgam informações contábeis e financeiras aos interessados pelo seu desempenho econômico. Esses usuários podem ser, por exemplo, acionistas, investidores ou analistas de mercado, que avaliam o valor das ações das empresas. A cada dia a dinâmica do mercado financeiro tem exigido maior velocidade das informações e a Internet tem sido considerada um canal de divulgação que potencializa as oportunidades na melhoria da qualidade das informações fornecidas.

A Contabilidade pode ser definida como um sistema cujo principal objetivo é fornecer informações úteis a seus usuários, de forma a apoiá-los na avaliação e na tomada de decisão econômica e financeira. Para tanto, trata de identificar, medir, registrar e comunicar os eventos econômicos de uma empresa, sendo considerada uma linguagem de negócios. (FRANCO, 1997).

O principal grupo ao qual se destinam as informações contábeis são os acionistas, investidores e credores. Esses dados podem ser divulgados através das demonstrações financeiras, (também chamadas demonstrações contábeis ou relatórios contábeis) e dados complementares (notas explicativas), discussão e análise da situação financeira e dos resultados operacionais pela administração da empresa (relatório da administração), além de dados financeiros selecionados, inclusive sobre o mercado de ações da empresa. Por outro lado, além dos acionistas, investidores e credores, existem outros interessados nas informações da empresa. Entre eles estão, funcionários, clientes, fornecedores, governo, e a sociedade em geral. (HENDRIKSEN e BREDA; 1999).

Muitas informações qualitativas são divulgadas voluntariamente pelas empresas brasileiras através do relatório 
conhecido como Balanço Social, que agrega valores sociais, ambientais e humanos das atividades empresariais.

O nível de divulgação de informações pela empresa depende de uma série de fatores. Alguns autores defendem que as empresas devem divulgar toda informação necessária para os acionistas, investidores e público em geral. Outros argumentam que as empresas não fornecem informações mais completas porque pode haver outras fontes de informações financeiras disponíveis a um custo mais baixo do que se fosse fornecida pela própria empresa (HENDRIKSEN e BREDA; 1999). De qualquer modo, a divulgação é vital para a tomada de melhores decisões possíveis e a divulgação oportuna de informação relevante tende a impedir a ocorrência de surpresas que poderiam alterar a percepção a respeito do futuro de uma empresa.

O potencial de divulgação de informações contábeis via Internet contribui para aprimorar o relacionamento das empresas com os diversos usuários das informações divulgadas por elas. WARE et al. (1998) definem seis características básicas da Web: interatividade, resposta imediata, conectividade, interoperabilidade, multimídia e facilidade de uso. Cada uma dessas características pode contribuir para incrementar a distribuição de informações financeiras das empresas aos usuários interessados.

Não foi possível, até o momento, determinar exatamente quando surgiu a contabilidade, mas, estima-se que sempre existiu; que o homem, não importando a época em que viveu, sempre procurou controlar suas finanças, medir seu patrimônio e, por mais rudimentar que fossem seus métodos, em todo espaço de tempo em que viveu, o homem utilizou técnicas contábeis.

Com a criação da pessoa jurídica, os relatórios contábeis passaram a influenciar as finanças de um número maior de interessados. Com as sociedades anônimas, surgiu, também, a necessidade de regulamentação, padronização e fiscalização da profissão contábil, por envolver o público externo. Essa atribuição, na maioria dos países, recaiu sobre o Estado.

Uma das finalidades da contabilidade é a orientação e controle na administração da empresa. Trata-se de um banco de dados, que envolve pessoas, técnicas de controle de dados que são capazes de informar em qualquer tempo a quantificação e qualidade de dado patrimônio, quer de pessoa física ou jurídica, para os fins a que se dispõe o indivíduo ou a entidade que investiu, no sentido de criar patrimônio.

A Contabilidade é uma ciência que permite, através do uso de técnicas particulares, controlar permanentemente o patrimônio da empresa. Segundo Franco (1997, p. 62),

é uma ciência aplicada, com finalidades objetivas,

úteis e imprescindíveis à ordem econômica e social, bem como ao progresso das instituições a serviço da sociedade.

As informações contábeis devem ser importantes e úteis, para que sejam desejadas pelos usuários e bem utilizadas, garantindo a verdade de um patrimônio, em determinado tempo.
A exigência de grandes volumes de capital, a criação de formas de sociedades que recebam capital de investidores, gerou a separação entre investidor e administrador. Assim, um dos principais objetivos da contabilidade passou a ser a elaboração de relatórios a proprietários que não administram o negócio, ou seja, investidores que acompanham o retorno esperado do seu investimento.

A Contabilidade visa fornecer aos usuários, independentemente de sua natureza, um conjunto básico de informações que, presumivelmente, deveria atender, igualmente, a todos, de forma consistente e clara. Auxilia, também, na tomada de decisão fora dos limites da empresa, através de relatórios contábeis que têm como objetivo básico prover informações úteis para a tomada de decisão econômica.

Outra finalidade é permitir decisões e julgamentos adequados por parte dos usuários da informação. Envolve um processo de participação entre usuário e contabilidade $e$ uma visão sistêmica da contabilidade dentro do processo ou sistema de informação empresarial. (PADOVEZE, 2002).

Informação é um tema muito estudado e comentado na literatura de diversas áreas do conhecimento. A ciência da informação surgiu de uma necessidade muito maior do que o acúmulo de dados ou informações, ou seja, da preocupação com o seu gerenciamento, difusão e organização. Os chamados usuários das informações têm interesse diferenciado em grau maior ou menor e, dependendo da informação que é disponibilizada, pode não ter valor algum para uns ou ser muito relevante para outros. As empresas lidam com todo tipo de informações diariamente e é importante que sejam gerenciadas para que se tornem úteis aos usuários interessados em tempo hábil, porque não terão valor algum se não atenderem a algum fim no momento certo.

As empresas têm várias funções sociais, por utilizarem recursos naturais, disponíveis para todo o tipo de público, materiais desenvolvidos por outras organizações e utilizam, também, recursos humanos. As empresas têm parceiros, seus fornecedores e clientes, que podem estar estabelecidos em regiões geográficas mais distantes.

Por ter relação direta com a sociedade, toda organização deve divulgar informações financeiras, econômicas e contábeis sobre suas atividades. Para isso, devem obedecer à legislação pertinente do(s) local(ais) em que opera(m).

No Brasil, as sociedades anônimas de capital aberto, na Bolsa de Valores, são obrigadas a publicar seus relatórios contábeis, também conhecidos como demonstrações financeiras, até o dia trinta de abril de cada ano e são fiscalizadas pela Comissão de Valores Mobiliários - CVM.

A necessidade de maior controle das informações, fiscalização e tributação, criaram o mercado financeiro. Não obstante as transformações na gestão dos negócios das empresas, a forma de divulgar suas informações financeiras passou por grandes mudanças, a mais recente e de grande impacto, foi a Internet.

\subsection{Contabilidade e meio ambiente}

Tendo em vista o constante debate sobre os efeitos negativos gerados por impactos ambientais provocados por 
décadas de desenvolvimento industrial, diversas áreas do conhecimento iniciaram a busca de alternativas para que a situação seja invertida, pois todos são afetados por tais impactos.

Desde meados da década de 1990, impulsionados principalmente por mudanças na lei de crimes ambientais brasileira, diversos autores da área contábil iniciaram estudos sobre a busca de conceitos e participação dessa ciência na temática em questão. No Brasil, os primeiros trabalhos acadêmicos a inserir a variável ambiental foram das autoras Ribeiro (1992, 1998 e 2005) e Ferreira (1998 e 2003).

Inserir a questão ambiental nos aspectos contábeis das atividades empresariais é uma tarefa bastante complexa, pois há uma conexão com outras áreas do conhecimento e, dessa forma, é preciso ter uma visão multidisciplinar do sistema empresa.

A contabilidade ambiental tem como objetivo medir o resultado das atividades das entidades relacionadas com 0 meio ambiente e esse deve ser divulgado através dos relatórios contábeis periodicamente. Para Ribeiro (2005, p. 45):

A contabilidade ambiental não é uma nova ciência, mas sim, uma segmentação da tradicional já, amplamente, conhecida. Adaptando o objetivo desta última, podemos definir como objetivo da contabilidade ambiental: identificar, mensurar e esclarecer os eventos e transações econômico-financeiros que estejam relacionados com a proteção, preservação e recuperação ambiental, ocorridos em um determinado período, visando a evidenciação da situação patrimonial de uma entidade.

No entendimento de Paiva (2003, p. 17),

A contabilidade ambiental pode ser entendida como a atividade de identificação de dados e registro de eventos ambientais, processamento e geração de informações que subsidiem o usuário servindo como parâmetro em suas tomadas de decisões.

Quanto à evidenciação de informações ambientais nos relatórios contábeis, de um modo geral, as empresas brasileiras utilizaram o relatório da administração e a maior parte das informações divulgadas são de natureza qualitativa, sem muita clareza, padrão e consistência, como verificaram diversos autores (SANTOS et al. 2001; NOSSA, 2002; PAIVA, 2003; MACHADO, 2003; CALIXTO, 2004). Dessa forma, os usuários externos das informações contábeis não têm condições de inferir sobre a situação econômica e financeira das empresas, considerando, também, o aspecto ambiental das suas atividades.

Apesar da escassez de informações ambientais divulgadas nos relatórios contábeis, autores como Ribeiro e Martins, (1993); Paiva (2003) e Machado (2003) constataram que diversas empresas investem em meio ambiente, apesar de não divulgarem, claramente, em seus relatórios tais investimentos, os mesmos existem e deveriam ser destacados contabilmente. Entretanto, a divulgação dessas informações, igualmente, poderia trazer benefícios para as empresas, sobre o aspecto decisório e gerencial (FROST e WILMSHURST, 2000; CARVALHO et al., 2000; GAGO, 2002 e TINOCO e KRAEMER, 2004).

Com base nesse cenário que pouco estimula, incentiva e conduz a pesquisa empírica em contabilidade ambiental, outros autores da literatura contábil criticam a falta de padronização na evidenciação contábil da variável ambiental, além da necessidade de auditoria contábil dessas informações, e que ela seja feita por empresa de auditoria independente. (BEETS e SOUTHER, 1999; BERGAMINI JUNIOR, 2000; O'DWYER, 200 I; NOSSA, 2002 e PAIVA, 2003).

Portanto, considera-se relevante a análise das informações ambientais divulgadas pelas empresas, de setores específicos ou de algum setor em particular, tendo em vista que o seu acompanhamento, comparação e divulgação dos resultados incentivará a ocorrência de mudanças no cenário atual.

Wilmshurst e Frost (2000) examinaram a relação existente entre a importância de variáveis que influenciam a decisão de divulgar informações ambientais e o que é praticado pelas companhias. Para esse fim, selecionaram uma amostra de 62 companhias australianas de vários setores e, como metodologia, utilizaram a análise de conteúdo para avaliarem a qualidade e quantidade de informações divulgadas nos relatórios das empresas. Os autores, também, enviaram um questionário para os Chiefs Finance Officers - CFOs das empresas selecionadas, com questões sobre a divulgação de informações ambientais evidenciadas nos relatórios anuais dessas companhias. Os resultados da pesquisa indicaram uma significativa correlação entre a importância percebida pelos CFOs e a divulgação de informações ambientais praticada pelas empresas componentes da amostra. Entretanto, conforme os resultados revelaram, os itens considerados importantes para os CFOs das companhias tiveram diferentes níveis, na decisão de divulgar informações ambientais.

Tilt (2001) teve como objetivo verificar se as políticas ambientais adotadas pelas companhias são evidenciadas em seus relatórios anuais. Para esse fim, analisou o conteúdo dos relatórios anuais e outros relatórios disponíveis no site de uma amostra de 75 das maiores companhias australianas, assim como, o envio de questionário, para verificação das políticas ambientais adotadas por elas. Os resultados obtidos pela autora indicaram muitas diferenças entre o conteúdo das políticas ambientais adotadas pelas companhias e o que é divulgado em seus relatórios e, de fato, poucas companhias divulgaram suas políticas ambientais em seus relatórios anuais.

Em sua tese de doutorado, Nossa (2002) analisou o conteúdo dos relatórios anuais das cinqüenta maiores empresas do setor de papel e celulose do mundo e como não fazia parte da amostra nenhuma empresa brasileira, o autor pesquisou também o disclosure ambiental das dez maiores empresas brasileiras do setor em questão, para fins de comparação com as empresas de outros países. Os resultados obtidos, de acordo com o autor, indicaram que o tema ainda é incipiente na literatura contábil e a divul- 
gação de informações ambientais ocorre principalmente no relatório da administração e em notas explicativas.

Num estudo exploratório, Patten (2002) verificou a relação entre a divulgação de informações ambientais contidas nos relatórios anuais com a performance ambiental de uma amostra de 122 companhias americanas incluídas no Toxic Releases Inventory - TRI de 1988, administrado pela Environmental Protection Agency - EPA. O programa TRI requer das empresas americanas um relatório que estime o nível de substancias tóxicas que são lançadas no meio ambiente. $\mathrm{O}$ autor utilizou a técnica de análise de conteúdo dos Formulários 10-K divulgados pelas companhias selecionadas, no período de 1985 a 1990. O relatório 10-K, assim como o relatório anual das companhias, é uma publicação disponível na Internet, entretanto, segundo o autor, o relatório 10-K, utilizado desde 1970, pelas companhias abertas registradas na Bolsa de Valores Americana, contém mais informações ambientais que o relatório anual. Entre suas conclusões, o autor verificou que a divulgação de informações ambientais é negativamente associada à performance ambiental da amostra selecionada. Os resultados obtidos sugeriram que a média de substâncias tóxicas emitidas pelas companhias analisadas, não necessariamente, induz a políticas de pressão pública e a mudanças no disclosure ambiental.

Com o objetivo de identificar os fatores que determinam a iniciativa de divulgar informações ambientais, a proposta de Cormier et al. (2004) foi verificar qual a percepção dos administradores em relação aos anseios dos stakeholders sobre as informações ambientais e como esse aspecto é divulgado contabilmente. Os autores enviaram um questionário para 41 companhias multinacionais norte-americanas e européias. Os resultados foram analisados através da estatística descritiva e demonstraram uma significativa relação entre o gerenciamento ambiental das companhias com as decisões que seus gerentes tomam, para responder aos anseios dos stakeholders, via relatórios anuais.

Tuwaijri et al. (2004) fizeram uma análise integrada de como a gestão estratégica das companhias afeta a divulgação de informações ambientais, o desempenho ambiental e a performance econômica das empresas. Os autores selecionaram uma amostra de 198 empresas americanas de capital aberto, trabalhando com as seguintes hipóteses: a performance econômica não está associada com a performance ambiental; a divulgação de informações ambientais não está associada com a performance ambiental e a performance econômica não está associada com a divulgação de informações ambientais. Utilizando técnicas da econometria e a análise de conteúdo, em suas conclusões, quanto ao potencial interno das companhias associado com as três variáveis analisadas, os autores constataram uma diferença estatisticamente significativa em suas inter-relações.

Num estudo sobre 291 companhias listadas na Bolsa de Valores de São Paulo, Silva e Magalhães Filho (2005) identificaram uma correlação entre o tamanho da empresa e a quantidade de informações financeiras divulgadas voluntariamente na Internet. Siqueira (2005) ressaltou o quanto os Bancos utilizam o potencial da Internet para disponibilizar informações financeiras para os seus clientes e usuários dessas informações, de um modo geral.

Com o objetivo de verificar a participação do setor bancário na divulgação de informações sociais e ambientais através da Internet, Coupland (2005) realizou um estudo de caso múltiplo, utilizando como amostra os cinco maiores grupos bancários que operam no Reino Unido. A autora analisou os aspectos da linguagem adotada pelas companhias para comunicação de informações sociais e ambientais através dos seus websites. De acordo com Coupland (2005, p. 14-15), apesar do crescimento da importância das considerações sobre responsabilidade social e ambiental dos Bancos, esse assunto é tratado perifericamente. Embora essas sejam evidências de que organizações estão começando a articular sobre esse tema em seus relatórios contábeis também disponibilizados via Internet, em decorrência do aumento da atenção e importância dadas a essas variáveis, a simples articulação ainda está longe de ser suficiente.

Razeed e Considine (2004) analisaram a tendência de as empresas usarem a Internet para disponibilizarem suas informações financeiras para todas as pessoas interessadas. Os autores buscaram identificar as informações ambientais divulgadas pelas empresas voluntariamente via Internet. Foi selecionada uma amostra aleatória de 126 companhias de vários setores, listadas na New York Stock Exchange e na Australian Stock Exchange (Bolsas de Valores Americana e Australiana) e com base na lista das 500 maiores companhias do mundo, divulgada pela Revista Fortune no período de 1999-2000. O foco da pesquisa foi comparar as informações divulgadas no relatório ambiental disponibilizado na Internet, com o relatório anual das companhias. Os autores confirmaram as seguintes hipóteses:

- O tamanho da empresa está significativamente associado com o nível de divulgação de informação sobre o meio ambiente nos relatórios anuais;

- Há uma associação entre o país de origem da organização e a extensão de informações ambientais divulgadas voluntariamente na Internet;

- Há uma associação entre o nível de penetração da Internet e a extensão dos relatórios sobre o meio ambiente divulgados voluntariamente na Internet;

- Há uma associação entre o nível de penetração da Internet e a extensão dos relatórios sobre o meio ambiente divulgados voluntariamente nos relatórios anuais. (RAZEED e CONSIDINE, 2004, p.20). (tradução livre)

Os autores acima verificaram, ainda, que, enquanto as companhias australianas divulgam mais informações ambientais em seus relatórios contábeis, companhias americanas utilizam a Internet em maior nível para divulgar esse tipo de informação.

A análise do referencial teórico permitiu verificar que ainda não foi pesquisada a relação entre o que as empresas brasileiras divulgam sobre o meio ambiente via relatórios contábeis com o que divulgam via Internet. 


\section{PROCEDIMENTOS METODOLÓGICOS}

Por ter maior potencial de poluir, as empresas dos setores analisados neste trabalho estão sujeitas à legislação ambiental mais rigorosa e isso varia de acordo com cada setor. Intuitivamente, quanto maior o potencial de poluir, maior o rigor da legislação para cada atividade. Portanto, foram selecionadas as sessenta maiores empresas brasileiras, classificadas pelo critério faturamento, de acordo com a publicação da Revista Exame, Melhores e Maiores, edição de 2005. A amostra foi intencional, ou seja, foram escoIhidas seis empresas de cada um dos dez setores potencialmente poluidores, assim classificados de acordo com o Instituto Brasileiro do Meio Ambiente e dos Recursos Naturais Renováveis - IBAMA, que são os seguintes: petroquímica, siderurgia e metalurgia, energia elétrica, papel e celulose, confecções e têxteis, mineração, mecânica, transportes, saneamento e alimentos.

As informações qualitativas e quantitativas sobre 0 meio ambiente divulgadas nos relatórios das companhias foram identificadas com base num disclosure index, neste estudo, chamado de índice de evidenciação. Baseado nas diretrizes recomendadas pelo UNCTAD/ISAR, para divulgação de informação sobre o meio ambiente nos relatórios contábeis, neste estudo foi desenvolvido um índice de evidenciação com vinte itens e baseado em vários trabalhos que também recomendaram um conjunto de diretrizes para divulgação de informações ambientais: Global Reporting Initiative - GRI (1997); Environmental Protection Agency - EPA (2003) e KPMG, $(1996,1999,2002)$, apresentados no quadro $1 \mathbf{0}$.

O desenvolvimento de cada item privilegiou informações ambientais qualitativas e quantitativas que podem ser divulgadas pelas companhias via relatórios contábeis publicados em jornais de grande circulação, impressos e solicitados diretamente às empresas ou, disponibilizados nos seus sites. A pontuação para evidenciação foi desenvolvida com base nas informações contidas nos websites, em ícone específico sobre o meio ambiente e nos relatórios contábeis das companhias.

Foram, então, examinados, minuciosamente, a evidenciação e a não-evidenciação dos itens selecionados. As companhias foram avaliadas em "1" para evidenciação e "0" para não-evidenciação das informações. O resultado foi quantificado para comparação entre empresas e setores.

\begin{tabular}{|c|l|}
\hline 1 & ÍNDICE DE EVIDENCIAÇÃO \\
\hline 2 & Peclaração/existência de evidenciação do interesse nas questões ambientais \\
\hline 3 & Padrões ambientais \\
\hline 4 & Performance x padrões ambientais \\
\hline 5 & Estrutura e responsabilidade nas mudanças empreendidas na organização para desenvolver sensibilidade ambiental \\
\hline 6 & Treinamento para consciência ambiental \\
\hline 7 & Reconhecimento das regulamentações ambientais \\
\hline 8 & Presença de uma gerência ambiental \\
\hline 9 & Reconhecimento dos impactos ambientais das atividades \\
\hline 10 & Presença de um sistema de gestão ambiental \\
\hline 11 & Programa ambiental de recuperação/reabilitação \\
\hline 12 & Envolvimento com projetos comunitários de educação ambiental \\
\hline 13 & Cumprimento de auditoria ambiental \\
\hline 14 & Montante gasto com recuperação ambiental \\
\hline 15 & Montante de multas relacionadas com não cumprimento da legislação ambiental \\
\hline 16 & Políticas de contabilidade ambiental \\
\hline 17 & Montante gasto com proteção ambiental \\
\hline 18 & Modelo/padrão de antecipação de gastos ambientais \\
\hline 19 & Avaliação de passivos contingentes \\
\hline 20 & Análise quantitativa de gastos com matérias-primas, energia e resíduos da produção \\
\hline
\end{tabular}

Fonte: Adaptado de Razeed e Considine (2003)

Quadro 1 | índice de evidenciação

\section{ANÁLISE DOS DADOS}

A análise da divulgação de informações nos relatórios contábeis permitiu identificar os setores que mais se des- tacaram: os de saneamento (17,5\%), seguido da mineração $(16,6 \%)$ e energia elétrica $(12,5 \%)$. Porém, as informações 
variaram por empresa de um mesmo setor. A evidenciação do interesse nas questões ambientais foi informada por $60 \%$ das companhias componentes da amostra e, do total, $32 \%$ das companhias divulgaram o montante gasto com proteção e/ou investimentos ambientais através do balanço social. O envolvimento com projetos comunitários de educação ambiental está presente nos relatórios contábeis de $23 \%$ da amostra.

A divulgação dos passos seguidos para monitorar 0 cumprimento das políticas estabelecidas e a estrutura e responsabilidade nas mudanças empreendidas na organização para desenvolver sensibilidade ambiental são dois itens que não foram destacados nos relatórios de nenhuma das companhias. Os setores que menos divulgaram informações ambientais através dos relatórios contábeis foram, respectivamente, alimentos (4,2\%), transportes $(5,0 \%)$ e mecânica $(5,8 \%)$.

A divulgação de políticas de contabilidade ambiental, assim como a performance versus padrões ambientais são os itens informados nas demonstrações contábeis de apenas $1,7 \%$ das companhias.

O nível de evidenciação ambiental nos relatórios contábeis das empresas componentes da amostra foi de 9,8\%. O Gráfico 10 apresenta os resultados por setor, de acordo o percentual de informações contábeis divulgadas em seus relatórios contábeis.

A análise das informações sobre o meio ambiente disponíveis na Internet permitiu identificar os setores que mais divulgaram: o de siderurgia e metalurgia $(43,3 \%)$, seguido do setor saneamento $(34,2 \%)$ e energia elétrica $(32,5 \%)$. Entretanto, assim como os indicaram o exame dos relatórios contábeis, as informações variaram por empresa de um mesmo setor e muitas não têm informação alguma sobre o meio ambiente em seu website (empresas dos seguintes setores: confecções e têxteis, mineração, mecânica, transportes e alimentos).

O disclosure do interesse nas questões ambientais foi destacado no website de $81,7 \%$ das companhias componentes da amostra. O envolvimento com projetos comunitários de educação ambiental, assim como a presença de um programa ambiental de recuperação e/ou reabilitação, estão presentes no website de $53,3 \%$ da amostra. Outro item de destaque entre as empresas foi a presença de um sistema de gestão ambiental, declarado por $46,7 \%$ das companhias.

A divulgação de políticas de contabilidade ambiental, assim como o modelo/padrão de antecipação de gastos ambientais são os itens informados no website de 1,7\% das companhias. Os setores que menos divulgaram informações ambientais via Internet foram respectivamente: confecções e têxteis $(10,0 \%)$, mecânica $(11,7 \%)$ e alimentos $(16,7 \%)$.

A divulgação de informações ambientais via Internet das empresas componentes da amostra atenderam o índice de evidenciação num total de $24,4 \%$ da amostra. O Gráfico 20 apresenta os resultados por setor, de acordo o percentual de informações contábeis divulgadas nos websites das empresas.

Ao comparar o conteúdo de informações ambientais divulgadas via relatórios contábeis com as informações divulgadas via Internet, observou-se uma diferença significativa, ou seja, foram encontradas mais que o dobro de informações divulgadas nos websites das companhias. Os setores de saneamento e energia elétrica foram os que mais se destacaram quanto ao disclosure nos relatórios contábeis e na Internet.

Os setores de alimentos e mecânica foram os que menos se destacaram na divulgação de informações via relatórios contábeis e via Internet, respectivamente. A divulgação de políticas de contabilidade ambiental é um item que não está presente nas demonstrações contábeis e nem nos websites de nenhuma das companhias componentes da amostra analisada.

O Gráfico $3-$ compara a performance das companhias para a divulgação via relatórios contábeis e via Internet:

A Tabela 10 apresenta um resumo dos índices de divulgação de informações ambientais nos relatórios anuais e na Internet. Nos relatórios contábeis, foram apresentadas as informações por setor, o percentual em relação ao total geral de empresas, a média de cada setor, assim como o desvio-padrão. Da mesma forma, foram apresentados os resultados da divulgação através da Internet.

Observe-se que a quantidade de informações divulgadas na Internet não está diretamente relacionada com a quantidade de informações divulgadas nos relatórios contábeis, assim como as empresas que se destacaram individualmente, não fazem parte dos mesmos setores. Apesar de a maioria das empresas componentes da amostra ter divulgado mais informações via Internet que nas demonstrações contábeis, verificou-se que esse fato está, necessariamente, relacionado com o seu potencial de poluir o meio ambiente, rigor da legislação associado ao seu setor e impactos ambientais de suas atividades, maior público de seus produtos, como foi o caso dos setores de fornecimento de energia elétrica e saneamento. 


\section{Evidenciação contábil por setor}

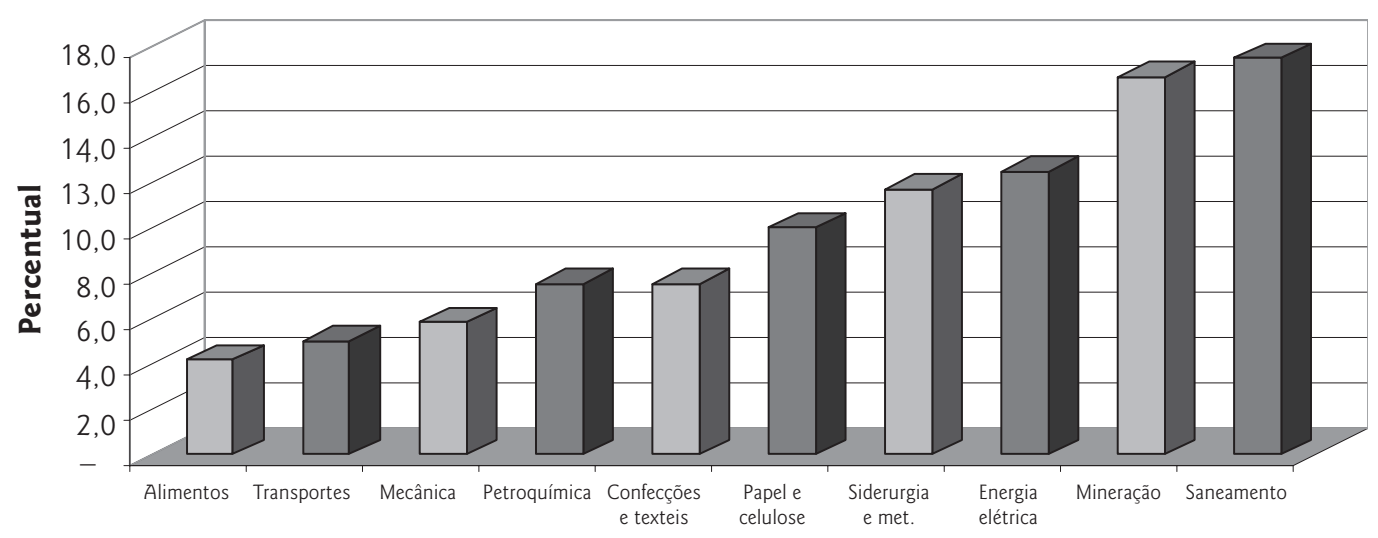

Fonte: Elaboração própria

Gráfico 1 ॥ Divulgação via relatórios contábeis

Divulgação via Internet por setor

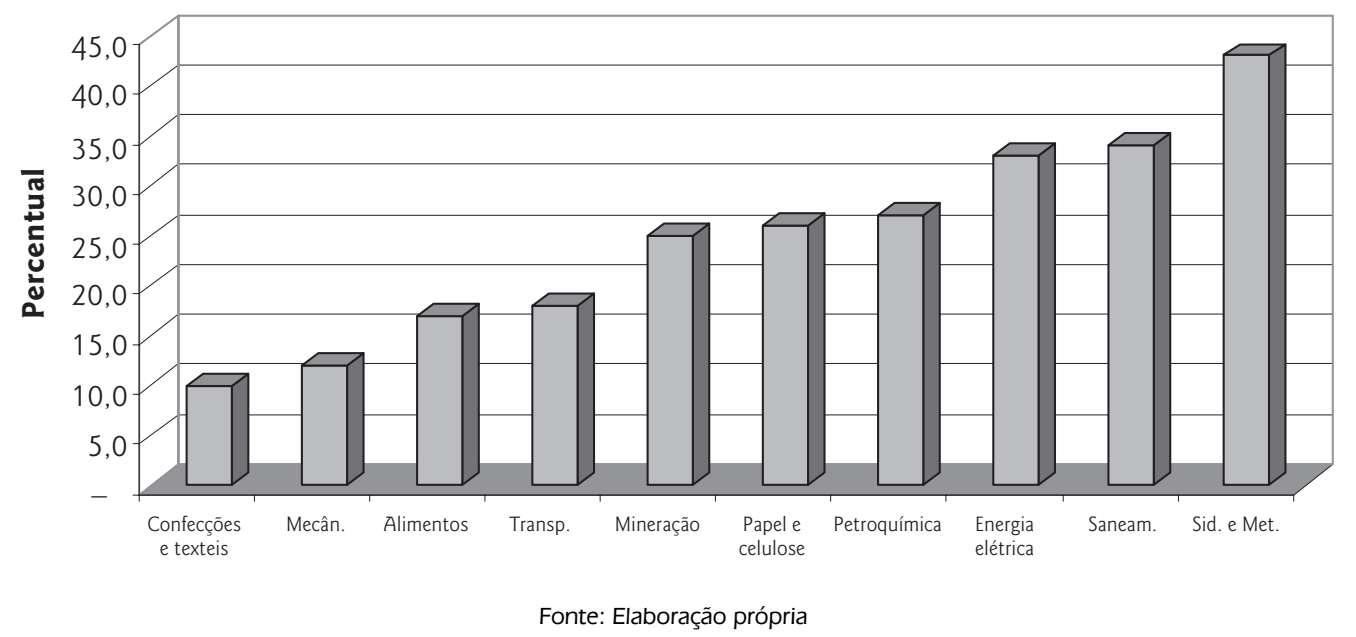

Gráfico 2 Informações divulgadas na Internet

\section{Demostrações Contábeis $\times$ Internet}

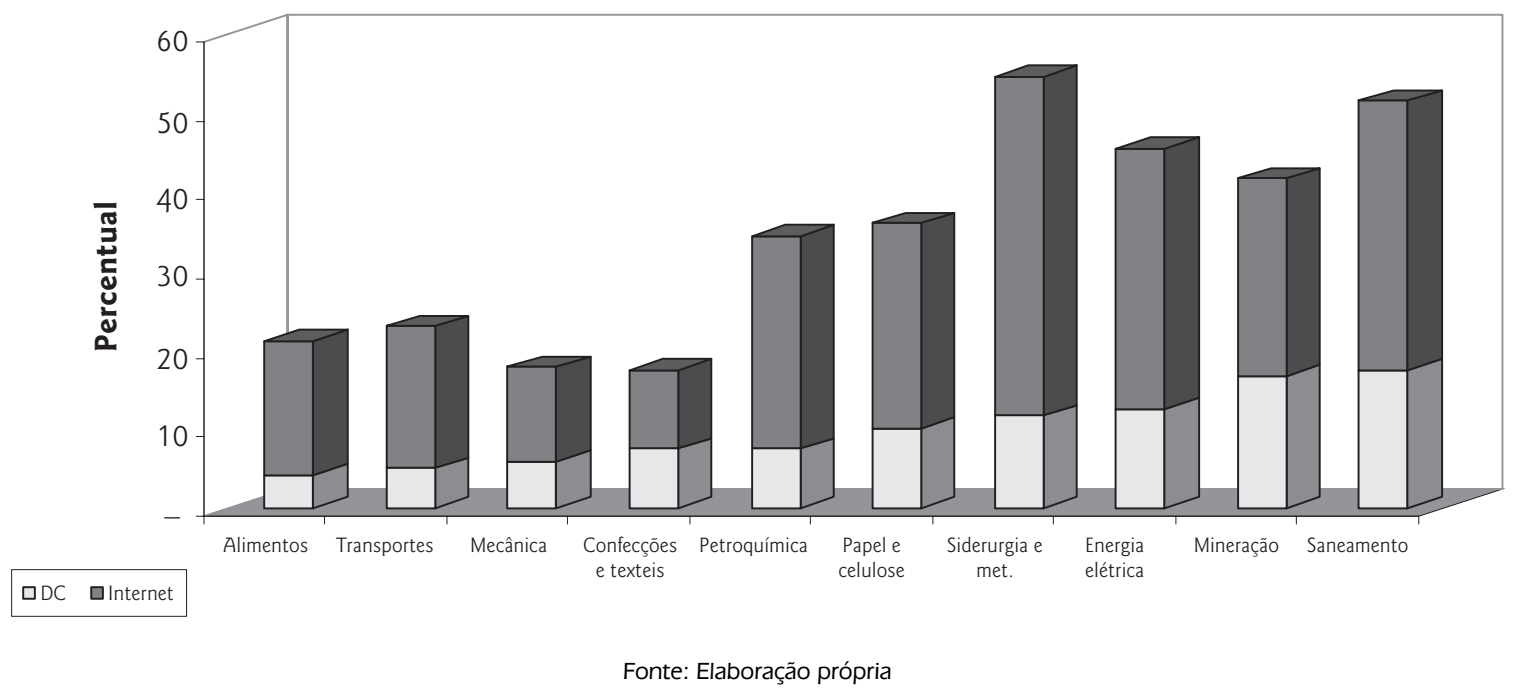

Gráfico 3 || Divulgação via Internet e via relatórios contábeis 
Tabela 1 Resultado geral ordenado por setor

\begin{tabular}{|c|c|c|c|c|c|c|c|c|}
\hline SETORES & $\begin{array}{l}\text { Relatórios } \\
\text { Contábeis }\end{array}$ & $\%$ & Média & $\begin{array}{l}\text { Desvio- } \\
\text { Padrão }\end{array}$ & Internet & $\%$ & Média & $\begin{array}{l}\text { Desvio- } \\
\text { Padrão }\end{array}$ \\
\hline Alimentos & 5 & 4,2 & 0,8 & 0,5 & 20 & 16,7 & 3,3 & 3,7 \\
\hline Transportes & 6 & 5,0 & 1,0 & 0,5 & 22 & 18,3 & 3,7 & 4,1 \\
\hline Mecânica & 7 & 5,8 & 1,2 & 0,4 & 14 & 11,7 & 2,3 & 2,0 \\
\hline Confecções e têxteis & 9 & 7,5 & 1,5 & 0,8 & 12 & 10,0 & 2,0 & 1,8 \\
\hline Petroquímica & 9 & 7,5 & 1,5 & 1,0 & 32 & 26,7 & 5,3 & 4,1 \\
\hline Papel e celulose & 12 & 10,0 & 2,0 & 1,1 & 31 & 25,8 & 5,2 & 4,3 \\
\hline Sid. e Metalurgia & 14 & 11,7 & 2,3 & 1,4 & 52 & 43,3 & 8,7 & 3,2 \\
\hline Energia Elétrica & 15 & 12,5 & 2,5 & 1,8 & 39 & 32,5 & 6,5 & 2,5 \\
\hline Mineração & 20 & 16,7 & 3,3 & 2,8 & 30 & 25,0 & 5,0 & 2,8 \\
\hline Saneamento & 21 & 17,5 & 3,5 & 1,4 & 41 & 34,2 & 6,8 & 1,2 \\
\hline Total Geral & 118 & 9,8 & & & 293 & 24,4 & & \\
\hline
\end{tabular}

Fonte: Elaboração própria

\section{CONSIDERAÇÕES FINAIS}

O objetivo deste trabalho foi identificar as diferenças na divulgação voluntária de informações ambientais via Internet e via relatórios contábeis de uma amostra de sessenta companhias que exercem atividades potencialmente poluidoras no Brasil, dos seguintes setores: petroquímica, siderurgia, metalurgia, papel e celulose, energia elétrica, alimentos, transportes, mecânica, saneamento, mineração e têxtil.

As informações relacionadas com o meio ambiente divulgadas via Internet e via relatórios contábeis de cada empresa foram segregadas por categoria e quantificadas conforme o índice de divulgação preestabelecido nesta pesquisa. Esse índice foi desenvolvido com base no referencial teórico recomendado por instituições que divulgam diretrizes globais sobre o tema.

Os resultados obtidos indicaram que os relatórios contábeis das empresas componentes da amostra atenderam o índice de evidenciação preestabelecido num total de 9,8\%. Esses resultados são similares aos de pesquisas anteriores, que identificaram a escassez de informações ambientais divulgadas nos relatórios contábeis, além de estarem presentes, principalmente, no relatório da administração e em notas explicativas e serem qualitativas.

A análise da divulgação de informações nos relatórios contábeis permitiu identificar os setores que mais se destacaram: saneamento $(17,5 \%)$, seguido de mineração $(16,6 \%)$ e energia elétrica $(12,5 \%)$. Porém, as informações variaram por empresa de um mesmo setor. Os setores que divulgaram menor quantidade de informações ambientais via relatórios contábeis foram respectivamente: alimentos (4,2\%), transportes $(5,0 \%)$ e mecânica $(5,8 \%)$.

A divulgação via Internet das empresas componentes da amostra atenderam o índice de evidenciação num total de $24,4 \%$ da amostra geral e, desse total, a análise da divulgação de informações sobre o meio ambiente na Internet permitiu identificar os setores que mais se destacaram: o de siderurgia e metalurgia (43,3\%), seguido do setor saneamento $(34,2 \%)$ e energia elétrica (32,5\%). Entretanto, da mesma forma que nas demonstrações contábeis, as informações variaram por empresa do mesmo setor. De fato, muitas companhias não divulgam informação alguma sobre o meio ambiente em seu website, empresas dos seguintes setores: confecções e têxteis, mineração, mecânica, transportes e alimentos. Os setores que menos divulgaram informações ambientais via Internet foram, respectivamente, confecções e têxteis (10\%), mecânica (11,7\%) e alimentos (16,7\%).

Ao comparar o conteúdo de informações divulgadas, via relatórios contábeis, com as informações divulgadas na Internet, observou-se uma diferença significativa, ou seja, encontrou-se mais que o dobro de informações na Internet. Entretanto, saneamento e energia elétrica foram os setores que se destacaram quanto ao disclosure nos relatórios contábeis e na Internet. Os setores de alimentos e de mecânica foram os que menos divulgaram informações via relatórios contábeis e via Internet.

Acredita-se que, por uma questão cultural das próprias empresas, muitas ainda não incorporaram a variável ambiental em seus processos, assim como o seu sistema contábil. Entretanto, entre empresas do mesmo setor, muitas destacaram informações ambientais, além de declararem a preocupação com o meio ambiente, enquanto outras não divulgam informação alguma, via relatórios contábeis ou através da Internet.

Considera-se relevante a divulgação de informações ambientais via relatórios contábeis ou através da Internet, como importante mecanismo para as empresas atenderem os interesses dos diferentes usuários das informações sobre elas.

Verificou-se, em estudos anteriores, que as empresas americanas divulgam mais informações ambientais via Internet que via relatórios contábeis enquanto na Austrália ocorre o inverso. 
Recomenda-se para pesquisas futuras a ampliação da amostra para outros setores potencialmente poluidores, a análise setorial mais abrangente, assim como o acréscimo de subitens de evidenciação ambiental e a comparação com empresas de outros países. Recomenda-se, ainda, a formulação de hipóteses, como a relação existente entre o setor e o porte das companhias e a quantidade de informações divulgadas sobre o meio ambiente, na Internet e nos relatórios contábeis.

\section{Referências Bibliográficas}

BEETS, S. D., SOUTHER, Christopher C. Corporate environmental reports: the need for standards and an environmental assurance service. Accounting Horizons v. 13 n. 2 p. 129-145, Jun. 1999.

BERGAMINI JUNIOR, Sebastião: Contabilidade ambiental. Pensar Contábil, Rio de Janeiro, CRCRJ, n.08, p. 17-22. maio/jul. de 2000.

BRANDÃO, Wladmir Cardoso. A Internet como fonte de informações pra negócio: um ensaio sobre a realidade da Internet brasileira. Perspectivas em Ciência da Informação. Belo Horizonte, v. 7, n. 1, jan./jun. 2004.

CALIXTO, Laura. Contabilidade Ambiental: aplicação do modelo do ISAR no setor de mineração. 2004, 147f. Dissertação de Mestrado. Faculdade de Administração e Finanças. Universidade do Estado do Rio de Janeiro. Rio de Janeiro.

CARVALHO, Luís Nelson; MATOS, Emmanuel R. Junqueira de; MORAES, Romildo de Oliveira. Contabilidade ambiental. Pensar Contábil n.8, ano III, maio/jul. de 2000, p. 31-38.

COUPLAND, Christine. Corporate social and environmental responsibility in web-based reports: currency in the banking sector? Critical Perspectives on Accounting.2005. Disponível em <www.elsevier.com./locate/cpa>. Acesso em 10/04/2005.

CORMIER, D.; GORDON, I. M.; MAGNAN, M.: Corporate environmental disclosure: contrasting management's perceptions with reality. Journal of Business Ethics. n. 49 p. 143-165, 2004.

EPA - Environmental Protection Agency. An introduction to environmental accounting as a business management tool: key concepts and terms. Washington: Office of Pollution Prevention and toxics. June, 1995.

EXAME. Melhores e Maiores. São Paulo: Abril, Jul. 2005.

FERREIRA, Aracéli Cristina de Sousa. Contabilidade ambiental: uma informação para o desenvolvimento sustentável. São Paulo: Atlas, 2003.

. Uma contribuição para a gestão econômica do meio ambiente - um enfoque sistêmico da informação. 1998, 135f. Tese de Doutorado. Faculdade de Economia, Administração e Contabilidade. Universidade de São Paulo, São Paulo.

FRANCO, Hilário. Contabilidade geral. São Paulo: Atlas. 1997.

FROST G.R.; WILMSHURST T. D.. The adoption of environment-related management accounting: An analysis of corporate environmental sensitivity. Accounting Forum, v. 24, n. 4, Dez. 2000.

GAGO, Susana. Management information for ecologically oriented decision-making: A case study of the introduction of co-generation in eleven Spanish companies. Accounting Forum, v. 16, n. 2, jun. 2002. P. 191-218.

GRI - Global Reporting Initiative. Draft 2002 sustainability reporting guidelines. April 2002. Disponível em <www.globalreporting.org > Acesso em 17/04/2005.

HENDRIKSEN, Eldon S.; BREDA, Michael F.Van, Teoria da Contabilidade. Tradução de Antonio Zoratto Sanvicente. São Paulo: Atlas, 1999.

KESSLER, Gary C.. Credit Unions and the Internet in the $21^{\text {st }}$ century. Constititon State Corporate Credit Union Annual Meeting. May 1998. Disponível em <www.vtac.org/tutorials/csccu.html>. acesso em 28/09/2005.

KPMG. Mining Survey of Global Reporting Trends-2003. África do Sul. 2003.97p.

$31 / 05 / 2004$

Environmental Consulting. Mining: A survey of global reporting trends-2000. Disponível em <www.kpmg.com>. Acesso em

\section{$31 / 05 / 2004$.} Acesso em 14/06/2004.

International survey of environmental reporting 1999. Disponível em $<$ http://cei.sunderland.ac.uk/envrep/kpmg1999.pdf $>$.

MIRANDA, Roberto C. da Rocha. O uso da informação na formulação de ações estratégicas pelas empresas. Ciência da Informação. Brasília, v. 28, n. 3, p. 284-290. set./dez.1999.

MOLLETTA, Sergio Roberto. Perfil do usuário da Internet no futebol: o tocedorn@uta do ensino médio do Cefet-PR/Curitiba. Dissertação de mestrado. 2002. Engenharia da produção e sistemas. Universidade Federal de Santa Catarina:

NOSSA, Valcemiro. Disclosure ambiental: uma análise do conteúdo dos relatórios ambientais de empresas do setor de papel e celulose em nível internacional. 2002. Tese (Doutorado). Faculdade de Economia, Administração e Contabilidade. Universidade de São Paulo, São Paulo.

O'DWYER B.. Corporate environmental reporting: the quest for mainstream acceptance in the midst of inconsistency and incomparability. Accountancy Ireland; Abr. 2001, p. 18-19.

PADOVEZE, Clóvis Luís. Sistemas de informações contábeis: fundamentos e análise. 3. ed., São Paulo: Atlas, 2002.

PAIVA, Paulo Roberto de. Contabilidade ambiental: evidenciação dos gastos ambientais com transparência e focada na prevenção. São Paulo: Atlas, 2003. 
PATTEN, Dennis M.. Media exposure, public policy pressure, and environmental disclosure: an examination of the impact of tri data availability. Accounting Forum, v. 26, n. 2, jun., 2002.

RAZEED, A.; CONSIDINE, B.. Green Companies - Do they exist on the web? Disponível em <www.aaanz.org/Web2002/accepted\%20_papers/ razeeda.pdf $>$. Acesso em 17/06/2004.

RIBEIRO, Maisa de Souza. Contabilidade Ambiental. São Paulo: Saraiva, 2005.

. Custeio das Atividades de Natureza Ambiental. 1998. Tese (Doutorado). Faculdade de Economia e Administração e Contabilidade. Universidade de São Paulo, São Paulo.

Contabilidade e Meio Ambiente. 1992. Dissertação (Mestrado). Faculdade de Economia, Administração e Contabilidade. Universidade de São Paulo. São Paulo.

; MARTINS, Eliseu. A informação como instrumento de contribuição da contabilidade para a compatibilização do desenvolvimento no envolvimento econômico e a preservação do meio ambiente. Caderno de Estudos n. 9 - São Paulo - FIPECAFI, out.1993.

SANTOS, Adalto de Oliveira; SILVA, Fernando Benedito da; SOUZA, Synval de; SOUSA, Marcos Francisco Rodrigues de. Contabilidade ambiental: um estudo sobre sua aplicabilidade em empresas brasileiras. Contabilidade \& Finanças FIPECAFI - USP, São Paulo, v. 16, n. 27, p. 89-99, set./dez.2001.

SILVA, Wesley Mendes da; MAGALHÃES FILHO, Paulo Azevedo de Oliveira. Determinantes da disseminação voluntária de informações financeiras na Internet. Revista de Administração de Empresas - Era Eletrônica, v. 04, n. 02, jul./dez. 2005. Disponível em <www.rae.com.br/ eletronica/index.cfm?FuseAction=Artigo\&Id=2388\&secao=artigos\&volume=4\&numero=2\&ano=2005>. Acesso em 07/03/2006.

TILT, Carol Ann. The content and disclosure of Australian corporate environmental policies. Accounting, Auditing \& Accountability Journal, v. 14, n. 2, p. 190-212. 2001.

TINOCO, João Eduardo Prudêncio; KRAEMER, Maria Elisabeth Pereira. Contabilidade e gestão ambiental. São Paulo: Atlas, 2004. 303p.

TUWAIJRI, Sulaiman A.; CHRISTENSEN, Theodore E.; HUGHES II, K. E.. The relations among environmental disclosure, environmental performance, and economic performance: a simultaneous equations approach. Accounting, Organizations and Society, 2004, n. 29 , p. 447-471.

UNCTAD/ISAR - United Nations Conference on Trade and Development/ Intergovernmental Working Group of Experts on International Standards of Accounting and Reporting. Environmental Financial Accounting and Reporting at the Corporate level. United Nations: Geneva, 1998. Disponível em < www.unctad.org/em/docs/c2isar.pdf>. Acesso em 03/06/2004

WARE, James; GEBAUER, Judith; ROLDAN, Malu; HARTMAN, Amir. The Search for Digital Excellence. CommerceNet Press. 1998.

O uso da Internet para a divulgação das informações financeiras dos bancos. Disponível em www.milenio.com.br/siqueira/tr094.htm acesso em 14/01/2005.

WILMSHURST, Trevor D.; FROST, Geoffrey R.. Corporate environmental reporting: A test of legitimacy theory. Accounting, Auditing \& Accountability Journal.v. 13, n. 1, p. 10-26, 2000.

\section{NOTA - Endereço dos autores}

Universidade do Estado do Rio de Janeiro Campus Francisco Negrão de Lima

R. São Francisco Xavier, $524-9^{\circ}$ andar - Bloco E

Rio de Janeiro - RJ

20550-900
Universidade Federal de Minas Gerais

Faculdade de Ciências Econômicas

Rua Curitiba, 832

Belo Horizonte - MG

30170-120 